\title{
A evolução do mercado de capitais brasileiro e o perfil do acionista minoritário no Brasil
}

\author{
THE DEVELOPMENT OF THE BRAZILIAN CAPITAL \\ MARKET AND THE PROFILE OF MINORITY \\ SHAREHOLDERS IN BRAZIL
}

\author{
Ana Carolina Rodrigues *
}

Resumo: O presente trabalho parte da descrição da formação e evolução do mercado de valores mobiliários brasileiro, e a partir daí, analisa sua relação com a cultura de investimentos do país, bem como, com o perfil do acionista minoritário no Brasil. Entre outras coisas, identificamos um mercado de valores mobiliários recente, desenvolvido a partir da década de 1960, pensado a partir da realidade norte-americana e com um histórico de graves fragilidades. Eventos como o chamado "crash de 1971", o famoso “caso Nahas" ocorrido em 1989, e o advento da Lei n. 9.457/97, que suprimiu diversos direitos dos acionistas minoritários com vistas a agilizar os processos de privatizações, são retomados de modo a evidenciar algumas das razões pelas quais o pequeno investidor, não raramente, tende a preferir investimentos em renda fixa ou no mercado imobiliário, por exemplo.

Palavras-chave: Mercado de Capitais; Acionistas Minoritários; Cultura de Investimentos.

Abstract: This paper is initiated with a description of the evolution of the Brazilian securities market, and from this point, it analyzes the relationship of this process with the Brazilian culture of investments, as well as, with the profile of the Brazilian minority shareholder. Among other things, we could identify a young securities market, developed from the decade of 1960 , inspired by the reality of USA and characterized by a historic of fragilities. Events as the crash of 1971, the famous case "Nahas" from 1989 and the edition of Law n. 9.457/97, which abolished several minority shareholders' rights to accelerate the privatization process, are studied in order to explain some of the reasons because the Brazilian population usually prefers to invest in the fixed income market or in real estate, for example.

* Mestre em Direito pela Escola

Keywords: Capital Markets; Minority Shareholders; Culture of Investments. 


\section{INTRODUÇÃO}

Este estudo tem por objetivo identificar os pontos centrais da cultura de investimentos do país, bem como, do perfil de acionista minoritário no Brasil. Para tanto, teremos como ponto de partida a descrição da formação e evolução do mercado de valores mobiliários brasileiro.

Essa análise permite-nos apontar quem são os acionistas minoritários no mercado de valores mobiliários. Em síntese, observamos que, historicamente, os acionistas minoritários não são, em sua maioria, pequenos investidores, mas sim investidores institucionais ou estrangeiros que, a despeito de serem minoritários, guardam participação relevante no capital social das companhias.

Apesar da tradicional preferência popular por investimentos em ativos de renda fixa ou no mercado imobiliário, a história do mercado de valores mobiliários brasileiro já contou com momentos de intensa participação do pequeno investidor. Essa participação, no entanto, se deu de forma eufórica e desastrosa, fundamentalmente movida por ondas de especulação. Dessa forma, a criação de um ambiente seguro, com mecanismos capazes de proteger o pequeno investidor contra abusos, é essencial para a retomada da confiança desse tipo de investidor, bem como, para recuperar e consolidar a reputação do mercado de capitais brasileiro.

Da mesma forma que o estudo do perfil do acionista minoritário brasileiro aponta para uma incipiente participação do pequeno investidor no mercado de valores mobiliários, ele revela a possibilidade de expansão desse mercado por meio da atração do pequeno investidor. Reconhece-se, destarte, uma oportunidade de crescimento do mercado de valores mobiliários brasileiro.

Neste trabalho mostraremos, ainda, um panorama dos movimentos de concentração e pulverização de capital acionário no mercado de capitais brasileiro. De acordo com esse panorama, é possível notar que a pulverização acionária, assim como a participação estruturada do pequeno investidor, é um fenômeno recente no Brasil.

\section{PANORAMA HISTÓRICO DO MERCADO DE VALORES MOBILIÁRIOS BRASILEIRO}

De acordo com a literatura, o mercado valores mobiliários brasileiro apresentou pouca relevância na economia do país até meados dos anos 1960 (COSTA, 2006, p.106). Essa realidade encontrava explicação em fatores como: 
(i) os elevados níveis de inflação; (ii) a precária organização das bolsas de valores mobiliários; (iii) o monopólio dos corretores públicos; (iv) a falta de legislação adequada; e (v) os ônus impostos pela Lei da Usura (MACARINI, 2008, p.153).

Até a primeira metade da década de 1960, os corretores atuantes na bolsa de valores mobiliários eram nomeados pelo governo; seus cargos eram de caráter hereditário e vitalício e eles gozavam de baixa remuneração. As bolsas de valores, por sua vez, eram organizadas de forma precária e a negociação de papéis ficava restrita a horários determinados.

Os investidores eram, em grande parte, especuladores, e a participação de investidores institucionais era irrelevante. Poucas companhias negociavam ações de sua emissão no mercado, e os níveis de liquidez eram baixos. $\mathrm{O}$ processo de formação de preços era nebuloso e baseava-se, principalmente, em rumores e dados imprecisos. Ademais, inexistia a obrigação de as companhias divulgarem demonstrações financeiras ou fornecerem informações acuradas ao mercado.

Adicionalmente, a tributação dos eventuais rendimentos resultantes da negociação das ações era alta, os índices de inflação vigentes à época eram extremamente elevados, e o crédito de longo prazo, escasso. Em termos de regulação, não havia órgão estatal responsável pela disciplina e pela fiscalização do mercado de valores mobiliários nem qualquer diploma que trouxesse elementos claros para distinguir os conceitos de companhia aberta e companhia fechada (MATTOS FILHO; PRADO, no prelo).

Em 1964, com a instauração do regime militar no Brasil, esse cenário começou a mudar. Iniciou-se um processo de reforma financeira e de reestruturação do mercado de valores mobiliários, que teve como ponto de partida o Programa de Ação Econômica do Governo, Paeg. Esse programa destinava-se à estabilização e desenvolvimento da economia brasileira, e tinha como uma de suas prioridades o aperfeiçoamento do sistema financeiro e do mercado de capitais nacional.

Para atingir os objetivos do programa, foi elaborado, entre outras coisas, um conjunto de reformas institucionais visando à reestruturação do sistema:

(i) Lei n. 4.357/64: autorizou a emissão de Obrigações do Tesouro Nacional, adotou a correção monetária e concedeu benefícios fiscais para investimentos no mercado de valores mobiliários;

SCIENTIA IURIS, Londrina, v.16, n.2, p.107-128, dez.2012 
(ii) Lei n. 4.380/64: criou o Sistema Financeiro de Habitação e novos programas de seguro social, o PIS e o Pasep, representando captação compulsória de poupança privada, e instituiu a correção monetária em contratos imobiliários; (iii) Lei n. 4.506/64: introduziu pela primeira vez o conceito de Sociedade de Capital Aberto e criou, para esta categoria de companhias, isenção de pagamento de imposto sobre lucros distribuídos; e

(iv) Lei n. 4.595/64: estruturou o sistema financeiro nacional por meio da criação do Conselho Monetário Nacional e o Banco Central do Brasil, de forma a extinguir a Superintendência da Moeda e do Crédito - SUMOC, e a competência do Banco do Brasil para fazer política monetária.

No ano seguinte, em 1965, o Banco Central da República do Brasil solicitou à Agência Internacional de Desenvolvimento, assistência técnica para fins de operação e regulamentação do mercado de valores mobiliários brasileiro. Em resposta a essa solicitação, foram enviados ao país, pelo período de duas semanas, um membro da Securities and Exchange Commission e um membro da American Stock Exchange.

No relato produzido pelos membros das entidades norte-americanas destacou-se a aparente (i) falta de credibilidade do mercado de capitais brasileiro; e (ii) a inexistência de uma cultura de investimentos em renda variável:

a parte do povo brasileiro que possuía economias, jamais teve por hábito investi-las em títulos. Imóveis e moedas estrangeiras têm sido o meio de aplicação mais popular. (...) ações de diversas companhias inexistentes são vendidas ao público; os preços dos títulos são manipulados com relativa facilidade e transações por funcionários de sociedades anônimas e de companhias de investimentos com base em informações não acessíveis ao público são frequentes. (POSER; ROTH, 1965, p.5-6).

No mesmo período foi editada a Lei n.4.728/65 (Lei de Mercado de Capitais) que regulamentava o mercado de capitais brasileiro e tinha como objetivo combater os principais problemas que afligiam o mercado, bem como, incentivar a destinação da poupança pública para a capitalização empresarial. Nesse sentido, Bulhões Pedreira afirmava que: "o desenvolvimento do mercado dependeria da execução da lei, de se criar o sistema, buscando investidores, expandindo a poupança, deslocando poupança dos imóveis e de outras formas de aplicação" (ALMEIDA, 1984).

De acordo com o exposto, é possível observar que até a primeira metade da década de 1960 a cultura de investimentos predominante no Brasil era 


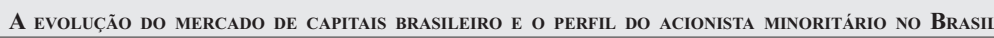

desfavorável ao mercado de capitais. No entanto, é nesse momento que parece surgir, pela primeira vez, uma política voltada aos investidores individuais. A ideia era estimular o crescimento do mercado de capitais por meio da poupança desses investidores

Assim, a Lei de Mercado de Capitais estabeleceu uma série de incentivos tributários para o investimento em ações e, também, para a abertura de capital das companhias (MACARINI, 2008, p.155-156). Nesse contexto, em 1967, foi instituído o Decreto-Lei n. 157, que trouxe novos incentivos ao investimento em ações. O referido diploma legal estabelecia a possibilidade de os contribuintes investirem parte do imposto de renda no mercado de ações por meio de fundos de investimentos. Esses fundos, por sua vez, aplicavam os recursos em companhias que preenchiam os requisitos legais exigidos.

Ressalta-se, contudo, que, se por um lado essa estratégia conduzia os pequenos investidores ao mercado, por outro, não havia qualquer preocupação em estimular uma participação consciente desses atores. Assim, o decreto-lei incentivava investimentos que acabavam mais por favorecer os administradores de fundos e os índices de mercado (no curto prazo) do que efetivamente fortalecer o mercado de valores mobiliários. $\mathrm{O}$ trecho abaixo ilustra bem essa situação:

Os primeiros fundos de investimento surgiram no Brasil no final dos anos 50 , mas só tomaram impulso após a criação dos Fundos de Ações DL 157, que criaram uma espécie de mercado cativo para a administração de fundos. Ou seja, o contribuinte do Imposto de Renda optava passivamente por aplicar parte do IR devido no fundo 157 administrado pela instituição financeira onde mantinha negócios. E como os recursos aplicados ficavam indisponíveis por muito tempo, o contribuinte transformado em condômino do fundo 157, tinha poucas condições e interesse de cobrar desempenho de tais fundos. Esses fundos incentivados estimularam as bolsas de valores e o mercado primário de títulos e, ao mesmo tempo, trouxeram bons retornos aos seus administradores, pelas seguintes razões: 1) desenvolveram a habilidade de administrar fundos voluntários de renda variável e fixa; 2) as taxas de administração eram, no geral, lucrativas; e 3) todos os ativos de má qualidade eram "descarregados" nesses fundos, porque os condôminos não cobravam desempenho. (SOUSA, 1998, p.34).

A participação de novos investidores no mercado acionário era estimulada de forma artificial, como mera alternativa ao pagamento de tributos. Assim, além de estimular as pessoas físicas ao ingresso despreparado e desinteressado

SCIENTIA IURIS, Londrina, v.16, n.2, p.107-128, dez.2012 
no mercado de valores mobiliários, essa política contribuiu, ao longo do tempo, para o desperdício de recursos públicos. A fala de José Luiz Bulhões Pedreira sobre o Decreto-Lei n. 157 corrobora essa posição:

No início funcionou, mas depois a experiência mostrou que esses incentivos [dos fundos 157] não dão resultados, ou funcionam muito limitadamente. É complicado criar algo dessa forma, artificial. Houve uma perda grande, recursos foram mal aplicados. Surtiu algum resultado, mas, se isso for comparado com o montante de impostos dirigidos para esse fim, não compensou.

Com o 157, todo mundo começou a ter estímulo para, em vez de pagar imposto, comprar ações. Qualquer um podia fazer e muitos tiveram a iniciativa, mas sem dar a menor importância para aquilo. Era apenas uma alternativa ao pagamento de imposto. Aplicava-se em empresas que só existiam no papel, por causa da questão tributária. (BARCELLOS, 2010, p.29).

Se por um lado as pessoas físicas não tinham real interesse de se tornar investidores do mercado de renda variável, por outro, as companhias investidas não tinham legítimo interesse de participar do mercado de capitais. De acordo com Ari Oswaldo Mattos Filho e Viviane Muller Prado, "o verdadeiro objetivo de abrir o capital era receber recursos de maneira facilitada e mais barata que o captado no sistema bancário" (MATTOS FILHO; PRADO, no prelo, p.14).

Em suma, os incentivos criados pela Lei de Mercado de Capitais e Decreto-Lei n. 157, somados à política econômica expansiva, impulsionaram o crescimento dos preços e volumes das bolsas. Nesse período, a política econômica manifestava "irrestrita simpatia no que se refere ao papel da Bolsa de Valores", em consequência, criava-se "um ambiente por demais propício ao surgimento de uma bolha especulativa" (MACARINI, 2008, p.161).

Esse ambiente de euforia, no entanto, estava em manifesto descompasso com a realidade do mercado de valores mobiliários brasileiro. De acordo com Lucy Aparecida de SOUSA (1998, p.23), "as razões para o crash estariam na falta de regulamentação adequada, na falta de conhecimento do investidor e na mudança das regras dos Fundos 157, que passaram a estimular as operações de mercado primário".

Assim, a crise de 1971 foi resultado de um ciclo iniciado por um período relativamente longo de gradual valorização de ações, sustentado por especuladores profissionais; posteriormente, a possibilidade de lucro fácil e rápido 
atraiu o capital de especuladores amadores, que passaram a sustentar e dinamizar o processo de aumento de cotações; em um terceiro momento, iniciou-se uma febre especulativa que, por sua vez, atraiu até mesmo indivíduos mais avessos ao risco movidos pela ideia de um enriquecimento coletivo; por fim, esgotadas as fontes de novos recursos, teve início um processo de queda de preços. Com isso, os especuladores profissionais rapidamente realizaram seu capital, de modo que aos especuladores amadores e aos investidores mais inocentes não restou outra saída a não ser arcar com o prejuízo final (BULHÕES PEDREIRA; LAMY FILHO, 1992, p.135-136).

Em consequência, o maior prejudicado foi o pequeno investidor, dado seu menor acesso a informações e sua ingenuidade perante os especuladores profissionais, como apontou Macarini (MACARINI, 2008, p.162):

a altíssima rentabilidade a curto prazo propiciada pela Bolsa - inteiramente apoiada pela política econômica, não revelando nenhum receio quanto aos riscos inerentes a um boom tão intenso - não deixaria de seduzir o pequeno investidor. Como é usual, a classe média afluiria em grande número quando a bolha já se aproximava de seu limite - desfazendo-se de bens tangíveis (automóvel, apartamento) ou mesmo endividando-se junto à rede bancária, na certeza de colher lucros mais que compensadores.

Assim, até o início dos anos 1970, o mercado de valores mobiliários vivenciou dois momentos antagônicos, quais sejam, um estado de dormência até a metade da década de 1960 e um boom no início da década seguinte. Em outras palavras, quando finalmente o pequeno investidor passou a mobilizar sua poupança para a aplicação no mercado de capitais, o resultado foi desastroso. Nitidamente, essa trajetória do mercado de capitais brasileiro abalou de forma negativa sua credibilidade perante o público investidor, sobretudo, os investidores não profissionais.

A deficiência do aparato regulatório vigente foi reconhecida após a crise e despertou esforços para o aperfeiçoamento da regulamentação do mercado, culminando na promulgação da Lei n. 6.404, e na criação da CVM por meio da Lei n. 6.385, ambas de 1976. Reconheceu-se, entre outras coisas, a necessidade de (i) criação de um sistema de informações adequado, com vistas a reduzir os níveis de assimetria de informações e o abuso na atuação de alguns agentes do mercado; (ii) substituir o Banco Central por um órgão especializado para fiscalizar o mercado de valores mobiliários; e (iii) aperfeiçoar os mecanismos de proteção dos investidores. 
Apesar das melhorias implantadas, a dívida externa brasileira obstou os investimentos em ativos do mercado de capitais. Os investimentos, em sua maioria, destinavam-se a aplicações financeiras lastreadas em títulos públicos.

Esse cenário apresentou uma relativa melhora no período de 1984-1986, em virtude da euforia e otimismo decorrentes do Plano Cruzado. O referido plano, no entanto, não tardou a apresentar fragilidades, e em 1986 um movimento de retração foi tomando o mercado.

Pouco depois, em junho de 1989, uma forte onda de especulação desencadeada pelo chamado "caso Nahas" culminou no fechamento temporário das bolsas de valores e na suspensão do mercado de opções até outubro de 1990. A partir desse evento restou claro que a atuação de um único investidor era capaz de comprometer toda a estrutura do mercado de capitais brasileiro. Dessa forma, os instrumentos de regulamentação e fiscalização mostraram-se absolutamente insuficientes para resguardar o mercado.

Em 1991, por sua vez, iniciou-se um processo de globalização financeira, privatizações e crescimento dos investidores institucionais. A entrada de investidores estrangeiros foi fortemente alavancada a partir da criação do Anexo IV à Resolução 1.287/87, incluído pela Resolução do CMN 1832/91. A partir da inclusão desse anexo, investidores institucionais estrangeiros podiam investir diretamente em valores mobiliários negociados no mercado brasileiro. Em outras palavras, foram abolidos os obstáculos até então existentes para o investimento estrangeiro direto no país, tais como, regras sobre capital mínimo; tempo de permanência ou formação de carteira; e obrigatoriedade de utilização de fundos ou sociedades como veículo de investimento. Ressalte-se, entretanto, que a participação dos investidores estrangeiros no capital social de companhias abertas deveria ser, obrigatoriamente, minoritária.

O aumento da participação estrangeira no mercado de valores mobiliários brasileiro trouxe relevantes alterações no perfil do investidor na Bolsa de Valores de São Paulo. Em relação ao volume de negociação, em 1991, os investidores estrangeiros representavam pouco mais de 5\%; em 1995 já somavam quase $30 \%$, tendo a sua participação reduzida a pouco mais de $20 \%$ no final dos anos 1990, em razão de crises internacionais (crise do México em 1994; crise dos países asiáticos em 1997; e crise da Rússia em 1998).

A quase totalidade dos investimentos de portfólios estrangeiros foi destinada à aquisição de ações de empresas estatais em processo de privatização (PRATES, 2001). A partir deste período, a credibilidade do mercado e a proteção aos acionistas minoritários foram atingidas por dois eventos relevantes. 
Em 1997, foi promulgada a Lei n. 9.457, conhecida como Lei Kandir. O referido diploma, com o objetivo de facilitar o processo de privatização, suprimiu relevantes direitos dos acionistas minoritários. Destacando-se aqui a exclusão do tag along e do direito de recesso em casos de cisão.

A Lei das S.A., antes da promulgação da Lei n. 9.457, exigia que, em casos de alienação de controle, fosse conferido tratamento igualitário entre acionistas minoritários e controladores, ou seja, o preço oferecido pelas ações dos acionistas não controladores deveria ser o mesmo daquele oferecido às ações do bloco de controle (tag along de 100\%). Esse mecanismo de proteção à minoria acionária foi completamente eliminado com o advento da Lei Kandir.

A referida supressão teve por escopo maximizar o valor arrecadado pelo governo no processo de privatização das empresas estatais. Em outras palavras, a referida reforma permitia ao Estado apropriar-se da integralidade do prêmio de controle, sem ter de dividi-lo com os demais acionistas ordinaristas.

O direito de recesso, por sua vez, foi suprimido para casos de cisão, com o propósito de reduzir os custos do governo nos processos de privatização. Dessa forma, excluiu-se o direito do acionista minoritário de não ser obrigado a continuar como sócio de uma companhia essencialmente diferente daquela cujas ações adquiriu (BULHÕES PEDREIRA; LAMY FILHO, 1992, p.339).

Posteriormente, em 2001 foi promulgada a Lei n. 10.303 que, entre outras coisas, restabeleceu o direito de recesso para casos de cisão e reincorporou o direito de tag along.

Nesse mesmo ano, foram criados os segmentos de listagem da BM\&FBovespa, quais sejam, Nível 1, Nível 2 e Novo Mercado. Cada um desses segmentos exige diferentes práticas de governança corporativa, com vistas a aumentar a proteção dos investidores. Em geral, os níveis de transparência e governança são maiores para o Novo Mercado. A criação dos segmentos de mercado representa um movimento a favor da valorização das práticas de governança corporativa e da proteção dos investidores.

Adicionalmente, em 2002, a Lei n. 10.411 alterou a Lei n. 6.385 dando mais autonomia adminitrativa para a CVM. Atualmente, a autarquia possui personalidade jurídica e patrimônio próprios, é dotada de autoridade administrativa independente, não apresenta subordinação hierárquica, goza de mandato fixo, garante estabilidade a seus dirigentes, e possui autonomia financeira e orçamentária.

A despeito da evidente evolução do mercado de valores mobiliários brasileiro, em 2008, mais uma vez, o mercado se viu em um momento de 
dificuldade: foi fortemente marcado por uma crise financeira originada nos Estados Unidos e disseminada, em maior ou menor escala, ao redor do globo. No Brasil, uma das nefastas consequências dessa crise foi a súbita apreciação do dólar norte-americano frente ao real, o que desencadeou prejuízos bilionários decorrentes de contratos de derivativos cambiais (RODRIGUES, 2010, p.113-134).

No mesmo ano, o Brasil também foi palco de um escândalo corporativo protagonizado pela Agrenco, empresa prestadora de serviços de comercialização e logística para o setor de agronegócios. Essa companhia foi alvo da operação "Influenza", realizada pela Polícia Federal, que culminou na prisão de vários de seus executivos, dentre eles os acionistas fundadores, sob a acusação de terem forjado balanços financeiros da empresa, a fim de ocultar desvios de recursos em benefício próprio (VALENTI; RAGAZZI, 2008).

Diante desse panorama fica claro que, ao longo do tempo, a evolução do mercado de valores mobiliários brasileiro ocorreu de forma instável e que a cultura de proteção do pequeno investidor é ainda recente.

Antes de 1965, o mercado de capitais brasileiro sequer contava com uma regulamentação minimamente consistente. No final da década de 1960 e início da década de 1970, o mercado vivenciou um momento de grande euforia, atraindo, inclusive, o pequeno investidor. Não obstante, o incentivo irrestrito ao investimento no mercado de capitais ocorreu de forma displicente e prematura, sem que houvesse, paralelamente, a preocupação em regulamentar o mercado e permitir o amadurecimento e a educação dos pequenos investidores. $\mathrm{O}$ resultado foi o crash de 1971 e, em consequência, uma profunda crise de credibilidade do mercado de valores mobiliários brasileiro.

A recuperação da confiança do mercado, a partir de então, sofreu novos golpes: o fechamento das bolsas de valores em razão do "caso Nahas", em 1989; a supressão de direitos dos acionistas minoritários, em 1997; e o escândalo corporativo da Agrenco e a crise de derivativos, em 2008. A conjugação desses eventos certamente contribui para a resistência do pequeno investidor à aplicação de sua poupança no mercado de valores mobiliários.

\section{OS MOVIMENTOS DE CONCENTRAÇÃO E PULVERIZAÇÃO DO CAPITALACIONÁRIO}

Tradicionalmente, o mercado de capitais brasileiro apresenta uma estrutura de capital eminentemente concentrado. "As companhias industriais, 
por tradição se têm mantido nas mãos de famílias ou pequenos grupos, sem qualquer interesse na venda de ações ao público, especialmente se dispõem de outras formas de financiamento" (POSER, 1965).

Essa estrutura se mostrou sustentável ao longo do tempo, já que diante do fechamento da economia, as necessidades de financiamento das companhias eram limitadas e, dessa forma, podiam ser supridas por meio de lucros retidos e de créditos comerciais e oficiais.

Por outro lado, quando havia necessidade de investimentos de maior monta, as companhias buscavam outras formas de financiamento mais convenientes e menos custosas. Em geral, recorria-se a recursos governamentais subsidiados, como, por exemplo, empréstimos junto ao BNDES (MB ASSOCIADOS, 2000, p.5).

Diante dessa realidade, a partir de 1964, o Governo Federal criou uma série de incentivos tributários para induzir o empresariado brasileiro à abertura de capital e direcionar a poupança privada para o mercado de valores mobiliários. Ressalte-se, entretanto, que, a despeito do ingresso de novas companhias nesse mercado, o poder de controle dos acionistas fundadores, em regra, permanecia inalterado.

A tendência de preservação do poder de controle dos acionistas fundadores, em grande medida, pode ser explicada pela possibilidade de extração de benefícios privados do controle. De acordo com estudo desenvolvido por Dyck e Zingales, baseados em uma amostra de 412 operações de venda de controle realizadas em 39 países no período de 1990 a 2000 no Brasil, os benefícios privados do controle atingiam $65 \%$ do equity value. Esse foi o valor mais elevado de todos os países da amostra - a média do valor do controle societário da amostra foi de aproximadamente 14\% do equity value (DYCK; ZINGALES, 2002).

Os níveis consideráveis de concentração acionária em companhias brasileiras foram evidenciados em uma série de estudos empíricos. Segundo pesquisa de Valadares e Leal (VALADARES; LEAL, 2000), realizada a partir de informações constantes nos IANs de 1996, em média, 74\% do capital votante de 203 das 325 companhias analisadas estavam concentrados nas mãos de um único acionista.

Nas 122 companhias em que o controle não era detido por um único acionista, o maior acionista detinha, em média, 32\% do capital votante. Considerando o total da amostra, (i) o maior acionista detinha, em média, 58\% do capital votante; (ii) os 3 maiores acionistas detinham $78 \%$ do capital votante; 
e (iii) os 5 maiores acionistas, detinham $82 \%$ das ações com direito de voto. Ademais, apenas $11 \%$ da amostra, 35 companhias, não possuíam ações sem direito de voto. De acordo com essa pesquisa, o capital das companhias analisadas era composto, em média, de $54 \%$ de ações com direito de voto e, $46 \%$ de ações sem direito de voto. As ações sem direito de voto funcionavam, em regra, como um mecanismo para separar controle e propriedade.

Na mesma linha, a pesquisa de Carvalhal-da-Silva e Leal, considerando uma amostra de 225 companhias, com base nas informações constantes dos IANS de 2000 , mostrou que $90 \%$ da amostra apresentava um acionista com mais de $50 \%$ do capital votante. Em média, esse acionista detinha $76 \%$ do capital votante e $54 \%$ do capital total da companhia. Nas 22 companhias onde não havia acionista controlador, o maior acionista detinha, em média, 37\% do capital votante. Considerando o total da amostra, (i) o maior acionista detinha $72 \%$ do capital votante; (ii) os 3 maiores acionistas detinham $85 \%$ do capital votante; e (iii) os 5 maiores acionistas detinham $87 \%$ das ações com direito de voto (CARVALHAL-DA-SILVA; LEAL, 2003). Ademais, o capital das companhias era composto, em média, de $53 \%$ de ações com direito de voto e $47 \%$ de ações sem direito de voto. Do total das companhias analisadas por esses autores, $48 \%$ eram controladas por famílias; $27 \%$, por investidores estrangeiros; e 7\%, pelo governo.

ALDRIGHI e OLIVEIRA (2007), por sua vez, analisaram propriedade e controle a partir de IANs de 1997 e 2002. Segundo essa pesquisa, 77,3\% das companhias listadas apresentavam um acionista controlador, e em 31,8\% delas o acionista controlador detinha mais de $90 \%$ do capital votante da companhia.

De acordo com dados constantes no White Paper on Corporate Governance in Latin America elaborado pela Organização para a Cooperação e o Desenvolvimento Econômico, OCDE, em 2003, mais da metade (51\%) das 459 sociedades abertas pesquisadas se concentravam na figura de um único acionista, e $65 \%$ das ações eram detidas pelos três maiores acionistas (COMPARATO; SALOMÃO FILHO, 2008).

Segundo pesquisa de GORGA (2008), baseada em dados de 2006 a 2007, a estrutura de capital concentrado predominava na maioria das companhias brasileiras, no entanto, a partir da criação dos segmentos especiais de listagem da BM\&FBovespa, vem ganhando relevo um movimento de pulverização da estrutura de capital das companhias.

Esse estudo mostrou que há uma relativa pulverização de capital nas companhias listadas no Novo Mercado. Conforme os dados da pesquisa, 65 
das 92 (aproximadamente 70,65\%) dessas companhias listadas não apresentam controle majoritário (entendido como aquele acionista, ou grupo de acionistas alinhados por meio de acordo de acionistas, que detém mais de $50 \%$ das ações com direito de voto). Nessas 65 empresas, os maiores acionistas detinham, em média, 26,23\% das ações; os três maiores, cerca de 47,28\% das ações; e os 5 maiores, $54,73 \%$ das ações.

Esse cenário de relativa dispersão acionária, no entanto, não predomina nos demais segmentos de listagem da BM\&FBovespa. No Nível 2, nas 20 companhias consideradas para a pesquisa, os maiores acionistas detinham, em média, $64,79 \%$ do capital votante. No Nível 1 , cerca de $63 \%$ das ações com direito de voto eram detidas pelo maior acionista, e quase $71 \%$ das companhias apresentavam um acionista controlador. Em relação às demais companhias abertas, que não participavam de nenhum dos segmentos citados e totalizavam uma amostra de 183 sociedades, pouco mais de $72 \%$ tinham acionista controlador. Nestas, os maiores acionistas detinham, em média, $65,5 \%$ das ações com direito de voto.

Da mesma forma que a pulverização parece muito mais presente entre as companhias listadas no Novo Mercado, esse segmento de listagem, ao que tudo indica, tem sido a principal opção para companhias que abrem o seu capital. De acordo com o estudo de GORGA (2008), das 92 companhias listadas no Novo Mercado em 2007, 77 eram novos entrantes e apenas 15 migraram de outro segmento.

Por meio da análise de dados da BM\&FBovespa, referentes ao período de 2004 a julho de 2011, foi possível confirmar a tendência de concentração das ofertas públicas iniciais no segmento do Novo Mercado. O gráfico 3 e o quadro 1 ilustram esse cenário.

Segundo os dados apresentados na tabela e no gráfico, é possível perceber que de 2004 a 2011, a grande maioria das companhias que abriu capital optou pela listagem no Novo Mercado: em 2004, 71\%; em 2005, 78\%; em 2006, 77\%; em 2007, 67\%; em 2008, 75\%; em 2009, 83\%; 91\% em 2010, 91\%; e até 29 de julho de 2011, 100\%.

Diante desses dados, é possível afirmar que caso essas duas tendências se confirmem (concentração de IPOs no Novo Mercado e maiores níveis de pulverização acionária nesse segmento de listagem), o processo de pulverização, ao longo do tempo, tende a intensificar-se. 
Gráfico 1 - Representatividade dos segmentos de listagem nas aberturas de capital na BM\&FBovespa.

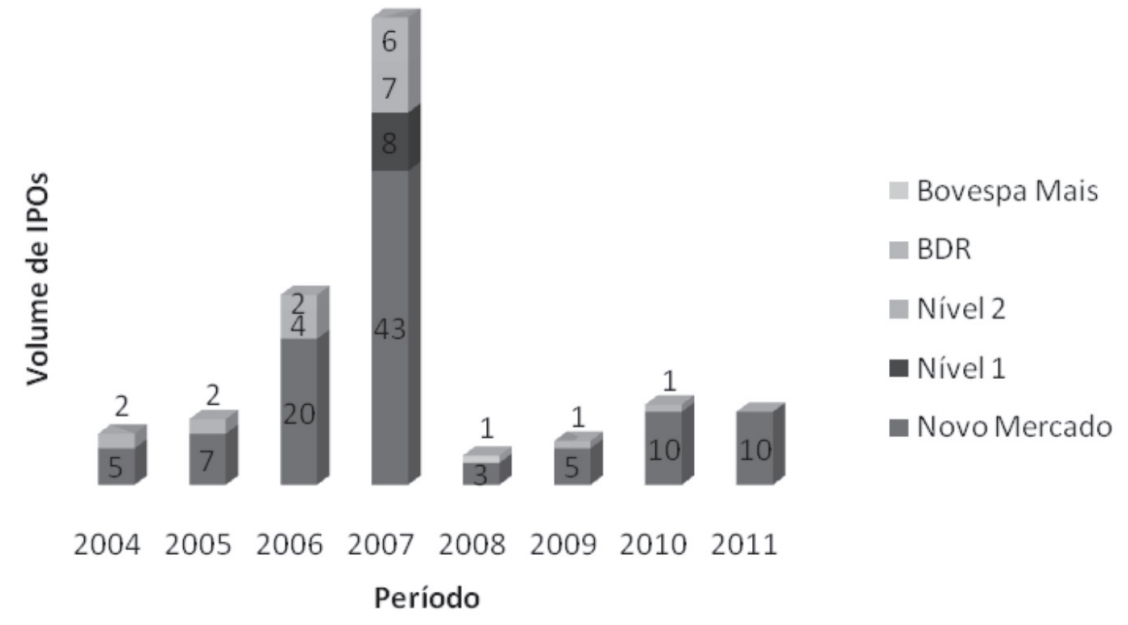

Fonte: dados oficiais da BM\&FBovespa.

Quadro 1 - Volume de IPOs para cada segmento de listagem da BM\&FBovespa.

\begin{tabular}{|ccccccc|}
\hline Período & $\begin{array}{c}\text { Novo } \\
\text { Mercado }\end{array}$ & Nível 1 & Nível 2 & BDR & $\begin{array}{c}\text { Bov espa } \\
\text { Mais }\end{array}$ & Total \\
\hline 2004 & 5 & 0 & 2 & 0 & 0 & 7 \\
\hline 2005 & 7 & 0 & 2 & 0 & 0 & 9 \\
\hline 2006 & 20 & 0 & 4 & 2 & 0 & 26 \\
\hline 2007 & 43 & 8 & 7 & 6 & 0 & 64 \\
\hline 2008 & 3 & 0 & 0 & 0 & 1 & 4 \\
\hline 2009 & 5 & 0 & 1 & 0 & 0 & 6 \\
\hline 2010 & 10 & 0 & 1 & 0 & 0 & 11 \\
\hline 2011 & 10 & 0 & 0 & 0 & 0 & 10 \\
\hline
\end{tabular}

Fonte: dados oficiais da BM\&FBovespa. 


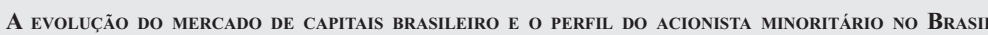

\section{O PERFIL DO ACIONISTA MINORITÁRIO NO BRASIL}

Conforme exposto, o ingresso de pequenos investidores no mercado de valores mobiliários brasileiro concentrou-se entre o final da década de 1960 e início da de 1970. Esse breve período de participação do pequeno investidor no mercado de capitais brasileiro ocorreu de forma desastrosa, culminando na crise de 1971.

Nos anos 1980, o mercado acionário brasileiro apresentou um fraco desempenho. O valor de mercado das companhias listadas em bolsa mantevese praticamente estagnado entre 1985 e 1992. No período de 1984-1986, contudo, as bolsas de valores brasileiras vivenciaram momentos de maior dinamismo, em razão da euforia gerada pelo Plano Cruzado, que reduziu as taxas de inflação. Não obstante, os problemas com o referido plano e as alterações na política econômica desencadearam um movimento de retração do mercado em 1986 (PRATES, 2001, p.43-44).

Entre o final da década de 1980 e início dos anos 1990, foi a vez de os investidores estrangeiros e institucionais assumirem o protagonismo no âmbito do mercado de capitais brasileiro.

A tabela 1 (SOUSA, 1998, p.31) e o gráfico $4^{1}$ a seguir demonstram a evolução do patrimônio de investidores institucionais ao longo do referido período.

Tabela 1 - Patrimônio dos investidores institucionais nos anos 1986 e 1987 (em US\$ bilhões).

\begin{tabular}{|cccccc|}
\hline Ano & $\begin{array}{c}\text { Fundos } \\
\text { Mútuos }\end{array}$ & $\begin{array}{c}\text { Fundos de } \\
\text { Pensão }\end{array}$ & Seguradoras & Total \\
\hline 1986 & 5 & 9 & 1 & 15 \\
1987 & 7 & 8 & 1 & 16 \\
1990 & 7 & 12 & 2 & 21 \\
1994 & 54 & 55 & 5 & 114 \\
1995 & 67 & 59 & 7 & 133 \\
1996 & 104 & 69 & 8 & 181 \\
1997 & 107 & 80 & 10 & 197 \\
\hline
\end{tabular}

Obs. 1: As seguradoras incluem os fundos de pensão abertos.

Obs. 2: Os dados de 1987 são preliminares.

Fonte: Anbid, Abrapp, Susep. 
Gráfico 2 - Evolução do patrimônio de investidores institucionais.

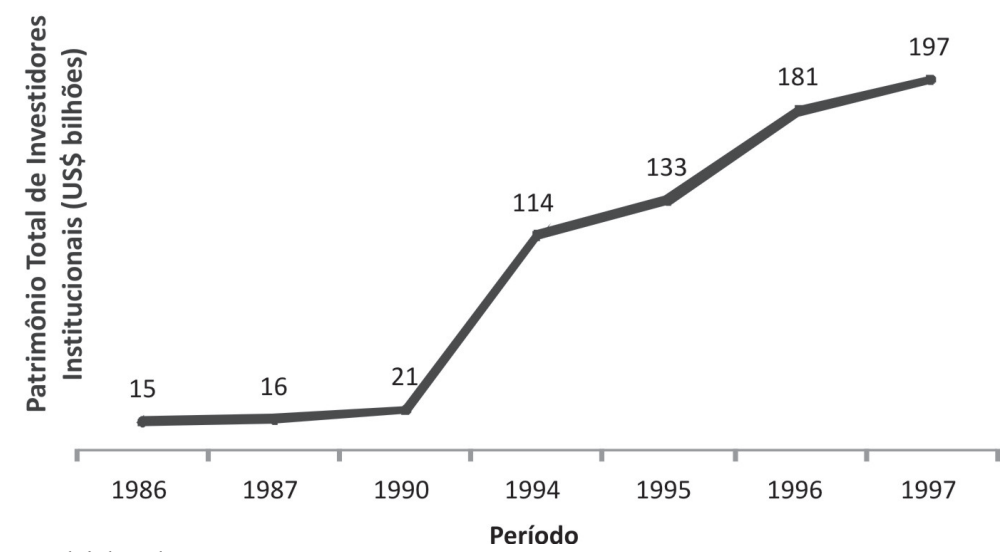

Fonte: Anbid, Abrapp, Susep.

De acordo com SOUSA, em 1997, o patrimônio dos investidores institucionais, que somava US\$ 197 bilhões, representava cerca de $25 \%$ do PIB do país. Tratava-se de uma participação significativa, que evidenciava a importância desse segmento de investidores.

Em relação aos investidores estrangeiros, também podemos observar significativo crescimento de seus níveis de participação no mercado acionário brasileiro: em 1993, 16\%; em 1994, 21,4\%; em 1995, 29,4\%; em 1996, 28,6\%; e em 1997, 25,9\% conforme ilustrado no gráfico 3.

Gráfico 3 - Participação de investidores estrangeiros na Bovespa, de 1993 a 1997.

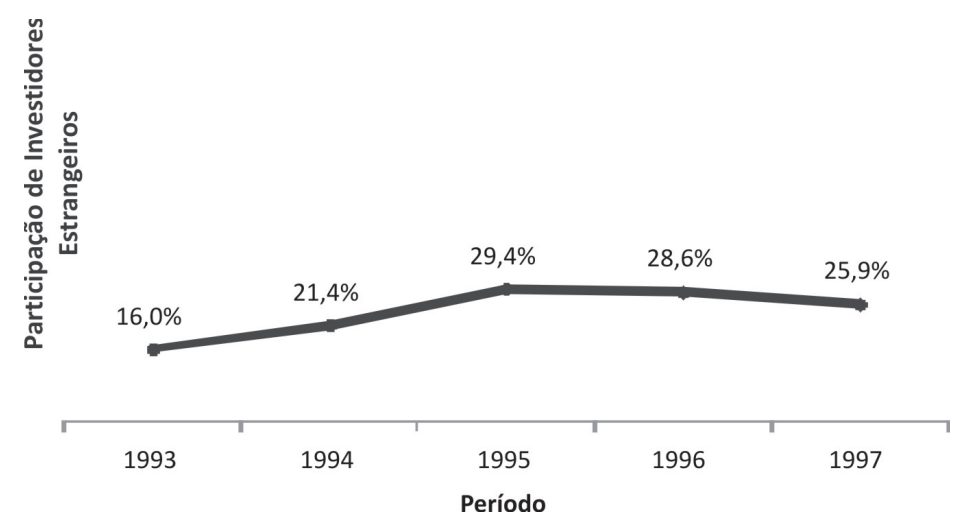

Fonte: Bovespa. 
O aumento dos investimentos estrangeiros nas bolsas de valores brasileiras foi impulsionado, sobretudo, pelos seguintes fatores: (i) movimento geral de expansão dos fluxos de capitais voltados aos mercados emergentes; (ii) diversificação internacional dos portfólios de investidores institucionais; (iii) abertura financeira do mercado acionário brasileiro; (iv) privatizações; e (v) potencial de valorização das bolsas de valores domésticas.

Note-se que os investimentos realizados por investidores estrangeiros concentraram-se em ações de empresas estatais em processo de privatização.

Atualmente, de acordo com o último Relatório Anual da BM\&FBovespa (2010), os investidores institucionais brasileiros apresentam os mais elevados níveis de participação no mercado acionário brasileiro, seguidos pelos investidores estrangeiros e pessoas físicas. Os investidores estrangeiros e institucionais brasileiros, juntos, representam $63 \%$ do volume negociado em 2010 . O gráfico 4 ilustra esse cenário:

Gráfico 4 - Segmento Bovespa: evolução do volume médio diário por grupo de investidores ( $\mathrm{R} \$$ bilhões).

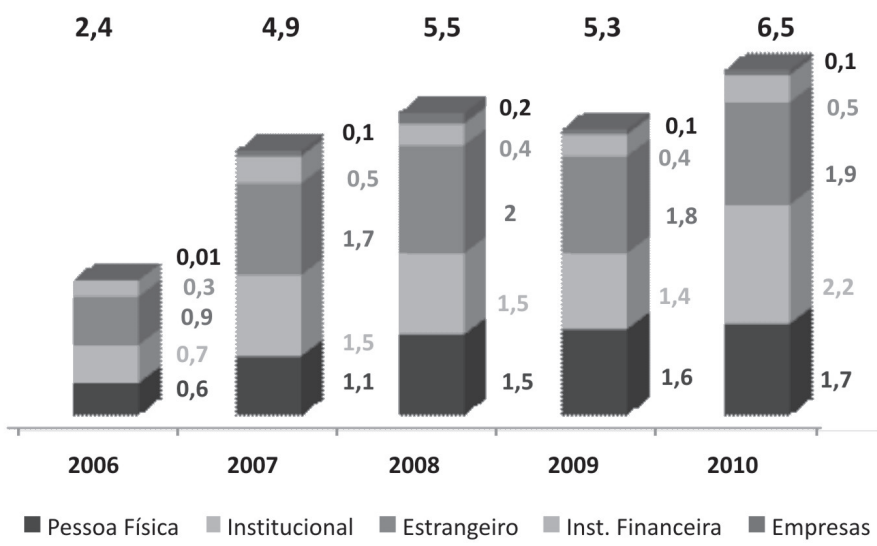

Fonte: Relatório Anual da BM\&FBovespa, 2010.

Se por um lado os investidores institucionais domésticos apresentam os mais elevados níveis de participação no mercado acionário brasileiro, por outro, os investidores estrangeiros adquirem a maior parte das ações em ofertas públicas. 
Fica claro que investidores institucionais e estrangeiros apresentam protagonismo no mercado de capitais brasileiro. Já as pessoas físicas ainda representam um nicho de mercado menos explorado. Por essa razão, em setembro de 2010, a BM\&FBovespa lançou a campanha "Quer ser sócio?", como parte de uma estratégia para captar 5 milhões de investidores em 5 anos. O objetivo da campanha é popularizar os investimentos no mercado de valores mobiliários por meio de educação financeira.

A educação de investidores e a educação financeira também têm sido objeto de atenção da CVM. Em 22 de dezembro de 2010, por meio do Decreto n. 7.397, foi instituída Estratégia Nacional de Educação Financeira, ENEF, como resultado de esforços conjuntos do Comitê de Regulação e Fiscalização dos Mercados Financeiro, de Capitais, de Seguros, de Previdência e Capitalização, Coremec, e de diversos órgãos e entidades públicas e privadas. Trata-se de política pública com o objetivo de proporcionar à população conhecimentos sobre planejamento, orçamento e consumo de produtos financeiros.

Dentre as iniciativas previstas na ENEF, destaca-se o Programa de Educação Financeira nas Escolas, conduzido com a participação de instituições dos setores educacional e financeiro, privado e público, sob a coordenação da CVM. Ademais, anteriormente à instituição da ENEF, teve início em 2010 o Projeto Piloto de Educação Financeira nas escolas de ensino médio, cuja primeira etapa foi concluída e envolveu cerca de 900 escolas e 27 mil estudantes de escolas do Ceará, Tocantins, Rio de Janeiro, São Paulo, Minas Gerais e Distrito Federal.

Com base no exposto, é possível notar que, pela primeira vez na história do mercado de valores mobiliários brasileiro, há uma preocupação com a captação sustentável do pequeno investidor.

Durante muito tempo, a participação dos pequenos investidores foi marginalizada ou incentivada de forma irresponsável. Em um cenário de informação escassa e alto risco, poucos investidores poderiam aplicar seus recursos sem incorrer em substanciais prejuízos. É possível afirmar que até pouco tempo os altos níveis de assimetria informacional e a precariedade dos mecanismos de proteção aos pequenos investidores, além de outros fatores, acabavam por restringir a atratividade do mercado de capitais para os investidores não profissionais. Essa realidade contribuiu para afastar o pequeno investidor do mercado de valores mobiliários. 


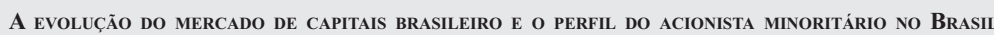

\section{CONCLUSÃO}

Ao longo do tempo, o mercado de capitais brasileiro passou por momentos de intensa instabilidade, potencializados, sobretudo, por ondas inflacionárias, estratégias políticas, crises financeiras, escândalos corporativos, supressão de garantias a investidores minoritários e crises internacionais.

A participação do pequeno investidor ganhou destaque no final da década de 1960 e início dos anos 1970. A atração desse investidor, no entanto, deu-se de forma inadequada. O estímulo à aplicação de recursos nos fundos 157 , por exemplo, induzia os contribuintes de imposto de renda a investirem no mercado de ações sem qualquer conhecimento sobre as políticas de investimento e funcionamento desses fundos. Incentivava-se, portanto, um investimento às cegas, sem que houvesse uma efetiva participação ou acompanhamento por parte dos investidores. Da mesma forma, durante o boom do mercado de capitais, pouco antes da crise de 1971, o governo federal manifestava sua simpatia irrestrita ao mercado de valores mobiliários brasileiro, o que acabou contribuindo para consolidar a ideia de que o mercado de capitais era um meio de enriquecimento fácil e rápido.

Diante deste contexto, os movimentos de especulação ganharam relevo e acabaram por culminar na crise de 1971. Além de perderem grande parte, quando não a totalidade, de sua poupança, os pequenos investidores perderam também a confiança no mercado de capitais brasileiro. Essa crise de credibilidade no mercado encontrou diversos motivos para estender-se: (i) fechamento das bolsas de valores (caso Nahas); (ii) supressão de direitos durante o processo de privatizações; (iii) escândalo corporativo da Agrenco; e (iv) crise de derivativos de 2008.

A despeito do cenário descrito, ao longo do tempo, algumas importantes melhorias foram implementadas no mercado de capitais brasileiro. A CVM passou por um processo de reestruturação e, atualmente, possui personalidade jurídica e patrimônio próprios, autoridade administrativa independente, ausência de subordinação hierárquica, mandato fixo e seus dirigentes têm estabilidade e autonomia financeira e orçamentária. Estas mudanças permitem à autarquia ter um desempenho melhor de suas funções, quais sejam, fiscalizar e zelar pelo bom funcionamento do mercado de valores mobiliários.

A preocupação com maiores níveis de transparência e a gradual adoção de práticas de governança corporativa inspiraram a criação dos segmentos especiais de listagem da BM\&FBovespa: Nível 1, Nível 2 e Novo Mercado. Esses segmentos contribuem para aumentar o comprometimento das companhias 
abertas diante de seus investidores e do mercado de capitais como um todo. A criação desses segmentos também contribui para a pulverização do controle acionário das companhias.

Por fim, ressalta-se que o aprimoramento do mercado de capitais brasileiro inclui a preocupação em educar a população, de modo a capacitá-la a fazer investimentos conscientes. O lançamento da campanha "Quer ser sócio?", concebida pela BM\&FBovespa em 2010, demonstra, pela primeira vez, uma preocupação não só em captar o pequeno investidor, mas também, capacitá-lo a investir e compreender o mercado de valores mobiliários brasileiro.

Diante do exposto, podemos concluir que o histórico do mercado de valores mobiliários brasileiro apresentou, ao longo do tempo, diversos aspectos capazes de desestimular o ingresso do pequeno investidor. Não obstante, parece haver uma preocupação recente em recuperar a credibilidade do mercado e atrair o pequeno poupador de maneira sustentável. Nesse contexto, os mecanismos de proteção a acionistas minoritários e o aprimoramento do mercado de capitais ganham especial relevo.

\section{REFERÊNCIAS}

ALDRIGHI, Dante Mendes; OLIVEIRA, Alessandro Vinícius Marques de.The Influence of Ownership and Control Structures on the FirmPerformance: Evidence from Brazil (March 15, 2007). Disponível em: <http://ssrn.com/abstract=972615>. Acesso em: 22 ago 2010.

ALMEIDA, J. S. G. As reformas financeiras de 1964-65: objetivos,rumos e desvios.IEI/UFERJ, 1984.

\section{BARCELLOS, Marta. Histórias do Mercado de Capitais no}

Brasil:depoimentos inéditos de personalidades que marcaram a trajetóriadas bolsas de valores do país. Rio de Janeiro: Elsevier; São Paulo:Bovespa, 2010.

Boletim de Empresas, 12a edição, Ano 2. Disponível em: $<$ www.bmfbovespa.com.br/empresas/boletim_empresas.asp $>$. Acesso em 10 ago 2010.

BULHÕES PEDREIRA, José Luiz; LAMY FILHO, Alfredo. A lei das S/A. Rio de Janeiro: Renovar, 1992. 
A EVoluC̣ão do mercado de Capitais brasileiro E O PERFIL do aCIONISTa Minoritário no Brasil

CARVALHAL DA SILVA, André; LEAL, Ricardo.

Corporategovernance, market valuation and dividend policy in Brazil 7(Coppead Working Paper Series, n.390, November 2003).Disponível em: $<$ http://ssrn.com/abstract=477302 $>$. Acesso em: 30 ago 2010.

COMPARATO, Fábio Konder; SALOMÃO FILHO, Calixto Salomão. Opoder de controle na sociedade anônima. Rio de Janeiro:

Forense, 2008.

COSTA, Roberto Teixeira da.Mercado de Capitais: uma trajetória de 50 anos. São Paulo: Imprensa Oficial do Estado de São Paulo, 2006.

DYCK, I. J. Alexander; ZINGALES, Luigi.Private benefits of control:an international comparison. National Bureau of Economic Research, Working Paper n. 8711, 2002.Disponívelem: <www.nber.org.papers/w8711>. Acesso em: 23 ago. 2010.

GORGA, Erica. Changing the Paradigm of Stock Ownership: FromConcentrated Towards Dispersed Ownership?Evidence from Braziland Consequences for Emerging Countries (April 2008).3rd AnnualConference on Empirical Legal Studies Papers.Disponível em: <http://ssrn.com/ abstract $=1121037>$. Acesso em: 11 mar. 2011.

MACARINI, José Pedro. Um aspecto da política econômica do"Milagre Brasileiro": A política de Mercado de Capitais e a bolhaespeculativa 1969-1971. Disponível em: <www.scielo.br>. Acesso em: 3abr. 2010.

MATTOS FILHO, Ary Oswaldo; PRADO, Viviane Muller. Tentativas dedesenvolvimento do mercado acionário brasileiro desde 1964. Artigopendente de publicação em 2011.

MB ASSOCIADOS. Desafios e Oportunidades para o Mercado deCapitais Brasileiro. Projeto realizado para a Bolsa de Valores de SãoPaulo. São Paulo, Maio, 2000.

OCDE. White Paper on Corporate Governance in Latin America.2003. 77 pp. Disponível em: <http://www.oecd.org/dataoecd/25/2/18976210.pdf $>$. 
POSER, Norman; ROTH, Allan. Pesquisa preliminar do mercado decapitais brasileiro. Banco Central do Brasil, 1965.

PRATES, Daniela M. Investimentos de portfólio no mercado financeirodoméstico. In: FREITAS, Maria Cristina P. (Org.) Abertura do sistemafinanceiro no Brasil nos anos 90. São Paulo: Edições Fundap-Fapesp, 1999.

Relatório Anual da BM\&FBovespa. Disponível em: $<$ http:// ri.bmfbovespa.com.br/upload/portal_investidores/PT/informaçõesfinanceiras/ relatórios_anuais/relatório-anual-2010.pdf>. Acesso em: 14 set. 2010.

RODRIGUES, Ana Carolina. A Crise de Derivativos Brasileira: Estudo doCaso Aracruz Celulose S.A. Revista de Direito Empresarial, n.14, jul./dez. 2010.

VALADARES, Sílvia Mourthé; LEAL, Ricardo Pereira Câmara.Ownership and control structure of Brazilian companies (2000).Disponível em: $<$ http://papers.ssrn.com/sol3/papers.cfm?abstract_id=213409>. Acesso em: 22 jul. 2011.

VALENTI, Graziella; RAGAZZI, Ana Paula.Escândalo da Agrencotestará mercado. Valor Econômico, 23 junho 2008. Disponível

em: $<$ www.biodieselbr.com/noticias/biodiesel/escandalo-agrenco-mercado-2306-08.htm>. Acesso em: 20 ago. 2010.

Recebido em: 2012-03-20

Aprovado para publicação em: 2012-12-17

Como citar: RODRIGUES, Ana Carolina. A evolução do mercado de capitais brasileiro e o perfil do acionista minoritário no Brasil. Scientia Iuris, Londrina, v.16, n.2, p.107-128, dez. 2012. DOI: 10.5433/2178-8189.2012v16n2p107. 